\title{
Smoking and older age associated with mumps in an outbreak in a group of highly-vaccinated individuals attending a youth club party, the Netherlands, 2012
}

G Ladbury (gladbury@gmail.com) ${ }^{1,2}$, S Ostendorf ${ }^{3}$, T Waegemaekers ${ }^{3}$, R van Binnendijk $^{1}$, H Boot $^{1}$, S Hahné $^{-}$

1. Dutch National Institute for Public Health and the Environment (RIVM), Bilthoven,

2. European Programme for Intervention Epidemiology Training, European Centre for

3. Municipal Health Service Gelderland Midden, Arnhem, the Netherlands

Ladbury G, Ostendorf S, Waegemaekers T, van Binnendijk R, Boot H, Hahné S. Smoking and older age associated with mumps in an outbreak in a group of highlyvaccinated individuals attending a youth club party, the Netherlands, 2012 . Euro Surveill. 2014;19(16): pii=20776. Available online: http://www.eurosurveillance. org/ViewArticle.aspx?Articleld=20776

We describe a mumps outbreak in a highly-vaccinated population attending a party at a youth club. In a retrospective cohort study with 60 of approximately 100 participants responding, vaccination status was verified for 58/59 respondents, of whom 54 were vaccinated twice and four once. The attack rate was $22 \%$ (13 cases, all vaccinated), with smoking at the party (risk ratio (RR) $3.1 ; 95 \%$ confidence interval $(\mathrm{Cl}): 1.6-6.0$, $\mathrm{p}=0.001$ ) and age $\geq 21$ years ( $R R$ 4.7; 95\% Cl: 2.1-10.2, p<0.0001) as risk factors for disease in the binominal regression analysis. Mild upper respiratory illness was also highly prevalent in those who did not meet the mumps case definition $(n=46)$ after the party, suggesting that mumps virus infection may cause mild disease in vaccinated individuals. Our investigation adds to evidence that crowded social events and smoking may facilitate spread of mumps virus among vaccinated populations, with waning immunity playing a role. The suggestion that mumps virus infection in vaccinated individuals may manifest as mild upper respiratory illness could have implications for transmission and warrants further investigation.

\section{Introduction}

Mumps is caused by a paramyxovirus infection and is characterised by acute swelling of the parotid and other salivary glands. Although usually mild, complications such as orchitis, pancreatitis, meningitis and deafness can occur. Routine mumps vaccination has been implemented in the Netherlands since a measles-mumpsrubella (MMR) vaccine containing the Jeryl Lynn virus strain was introduced into the National Immunisation Programme in 1987. This vaccine is offered as a twodose schedule at 14 months and nine years of age. Although vaccination coverage with two doses has consistently exceeded 93\% [1], several outbreaks in highly vaccinated populations have occurred recently, particularly in students [2-4]. These incidents contribute to growing evidence that high vaccine coverage may not suffice to prevent outbreaks $[5,6]$.
In spring 2012, a mumps outbreak occurred in a Dutch village with 25 cases notified to the municipal health service (MHS). Dates of onset for the notified cases ranged from 17 February to 2 April 2012, and three of these cases were laboratory-confirmed as infected with mumps virus genotype $\mathrm{G}_{5}$. Of 23 cases who could be contacted by the MHS, 22 were confirmed to have been vaccinated twice (the remaining case was born outside the Netherlands and had no accessible vaccination record). Eighteen of the 23 cases reported attending a party with approximately 100 guests at a youth club on 9 March 2012. We conducted a retrospective cohort study to investigate attack rates (AR) and risk factors for mumps disease at the party, and to explore the hypothesis that infection of vaccinated individuals may manifest as mild upper respiratory illness (URI).

\section{Methods}

We used an online questionnaire (Questback), publicised largely through social media, and active from 4 May to 4 June 2012, to collect information from party attendees regarding demographics, vaccination status, party-related activities (see Table 1), mumps history, and symptoms of mild upper respiratory illness/ mumps-like illness within 25 days of the party (the maximum incubation period) and also at the time they completed the questionnaire [7]. We defined cases as respondents with self-reported mumps (swelling of one/both cheeks with symptoms lasting $\geq$ two days) within 12 to 25 days after the party (the minimum and maximum incubation period), i.e. between 21 March and 3 April 2012. Vaccination status was verified using the national register. We explored associations between risk factors and mumps using univariable analysis and then binomial regression, entering all variables with p<0.20 into the model. To investigate the prevalence of mild respiratory illness around the time of the outbreak, we used McNemar's test to compare the prevalence of URI-specific (runny nose, sore throat, cough, and swollen cervical lymph nodes) and other 
TABLE 1

Questions about party-related activities included in questionnaire sent to people who had attended a youth club party in a village in the Netherlands on 9 March 2012

\begin{tabular}{|l|l|}
\hline Activity & Possible response \\
\hline Time of arrival at party & HH:MM (24h clock) \\
\hline Time of departure from party & HH:MM (24h clock) \\
\hline Number of people you spoke for >5 minutes at the party & $\begin{array}{l}10 \\
10-20 \\
21-30 \\
\text { '30 }\end{array}$ \\
\hline Did you spend time with friends before going to the party? & Y/N \\
\hline Did you go to another party/bar after leaving the youth club party? & Y/N \\
\hline During the party, did you do any of the following things: & \\
\hline Smoke a cigarette & Y/N/Don't know or prefer not to say \\
\hline Share a cigarette/cannabis joint & Y/N/Don't know or prefer not to say \\
\hline Share a drink (e.g drink from a glass or bottle that another person had used) & Y/N/Don't know or prefer not to say \\
\hline Share food with someone (e.g. use a fork or plate that another person had used) & Y/N/Don't know or prefer not to say \\
\hline Kiss someone & Y/N/Don't know or prefer not to say \\
\hline
\end{tabular}

N: no; Y:yes.

symptoms (stomach ache, myalgia, fever and loss of appetite) within 25 days of the party to the point prevalence of these symptoms at time of questionnaire completion, excluding mumps cases from this analysis. We performed analysis using Stata 11 . The study adhered to national ethical guidelines for health research [8-10].

\section{Results}

In total, 60 eligible questionnaires were returned. The exact number of people who attended the party is not known, but was estimated to be about 100. We do not know how many people saw the questionnaire, but the approximated response rate is $60 \%$. One individual with confirmed mumps with date of onset before January 2012 was excluded from analyses. The age range of the respondents was $15^{-25}$ years old (median $18)$, and $51 \%$ were male $(n=30)$. Vaccination status was verified for $58 / 59$ (98\%) respondents, of whom 54 were known to have been vaccinated twice and four at least once. The remaining respondent's vaccination status was unknown. Thirteen respondents met our case definition for mumps, equivalent to an $A R$ of $22 \%$. Nine of these cases had been notified to the MHS. One case had been laboratory-confirmed and eight reported confirmation by a physician. Incubation period ranged from 13 to 24 days (i.e. date of onset between 22 March and 2 April 2012), with a median of 18 days and a peak at 17-18 days (27-28 March 2012, see Figure). All 13 cases had been vaccinated twice. None of the

\section{FIGURE}

Number of cases of mumps associated with attending a village youth club party on 9 March 2012, by date of symptom onset, the Netherlands, March-April $2012(\mathrm{n}=11)$

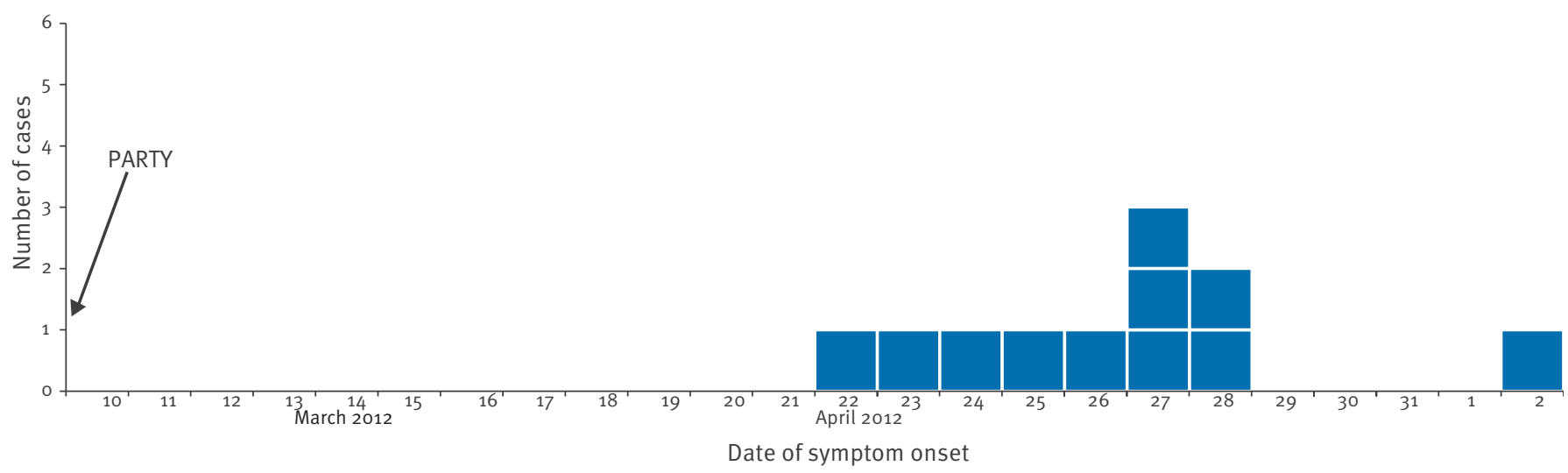


TABLE 2

Characteristics of and risk factors for mumps disease among questionnaire respondents after a youth club party in a village, the Netherlands, 9 March $2012(\mathrm{n}=59)$

\begin{tabular}{|c|c|c|c|c|c|c|c|c|}
\hline \multirow{2}{*}{\multicolumn{2}{|c|}{ Variable }} & \multirow{3}{*}{$\begin{array}{l}\mathrm{N} \\
30 \\
\end{array}$} & \multirow{3}{*}{$\begin{array}{c}\text { Cases } \\
\text { (n) } \\
8\end{array}$} & \multirow{3}{*}{$\begin{array}{c}\begin{array}{c}\text { Attack } \\
\text { rate } \\
(\%)\end{array} \\
27 \\
\end{array}$} & \multicolumn{2}{|c|}{ Univariable analysis } & \multicolumn{2}{|c|}{ Binomial regression } \\
\hline & & & & & \multirow{2}{*}{$\begin{array}{c}\begin{array}{c}\text { Risk ratio } \\
(95 \% \mathrm{Cl})\end{array} \\
1.5(0.5-4.0) \\
\end{array}$} & \multirow{2}{*}{$\begin{array}{l}p \text { value } \\
0.534\end{array}$} & \multirow{2}{*}{$\begin{array}{c}\begin{array}{c}\text { Risk ratio } \\
(95 \% \mathrm{Cl})\end{array} \\
\mathrm{NA}\end{array}$} & \multirow{2}{*}{$\begin{array}{c}\text { p value } \\
\text { NA }\end{array}$} \\
\hline Sex & Male & & & & & & & \\
\hline & Female & 29 & 5 & 18 & Reference & - & - & - \\
\hline \multirow[t]{2}{*}{ Age group } & $<21$ years & 48 & 7 & 15 & Reference & 0.005 & $4.7(2.1-10.2)$ & $<0.0001$ \\
\hline & $21+$ years & 11 & 6 & 55 & $3.7(1.5-8.7)$ & - & - & - \\
\hline \multirow{3}{*}{$\begin{array}{l}\text { Vaccination } \\
\text { status } \\
\text { against } \\
\text { mumps }\end{array}$} & Two doses & 54 & 13 & 24 & - & - & - & - \\
\hline & Vaccinated but number of doses unknown & 4 & 0 & 0 & - & - & NA & NA \\
\hline & Unknown status & 1 & 0 & 0 & - & - & - & - \\
\hline \multirow[t]{3}{*}{ Education } & Full time & 45 & 8 & 18 & $0.5(0.1-2.0)$ & 0.385 & - & - \\
\hline & Part time & 8 & 3 & 38 & $1.1(0.3-4.8)$ & - & NA & NA \\
\hline & None & 6 & 2 & 33 & Reference & - & - & - \\
\hline \multirow{2}{*}{$\begin{array}{l}\text { Smoked } \\
\text { cigarette at } \\
\text { party }\end{array}$} & No & 44 & 7 & 16 & Reference & 0.050 & $3.1(1.6-6.0)$ & 0.001 \\
\hline & Yes & 13 & 5 & 42 & $2.6(1.0-6.8)$ & - & - & - \\
\hline
\end{tabular}

$\mathrm{Cl}$ : confidence interval; NA: not applicable; Reference: reference group; -: denotes a result that cannot be calculated

For one respondent, information on self-reported mumps symptoms was missing, therefore ARs and RRs are calculated with $n=58$ as denominator

respondents reported complications (meningitis, orchitis, pancreatitis or deafness) or hospitalisation.

Table 2 shows the results of the univariable and multivariable analyses. Respondents aged $\geq 21$ years had a significantly higher AR (54.6\%) than those under 21 (14.9\%), (risk ratio (RR) 3.7; 95\% Cl: 1.5-8.7, $\mathrm{p}=0.005$ ). Respondents who smoked at the party also had a higher AR (41.7\%) than non-smokers (15.9\%); this result approached significance (RR $2.6,95 \% \mathrm{Cl} 1.0-$ $6.8, p=0.05)$. No other variables had $p<0.20$ in univariable analysis. Both factors remained significant in binomial regression: RR for age $\geq 21$ years was 4.7 ( $95 \%$ $\mathrm{Cl}: 2.1-10.2$, p 0.0001$)$, and for smoking at the party 3.1 ( $95 \% \mathrm{Cl}: 1.6-6.0, p=0.001)$.

Table 3 shows the results of the symptoms analyses. Symptoms that were significantly more prevalent in the 25 days after the party compared to the time of questionnaire completion were all URI-specific, namely sore throat $(p=0.0016)$, cough $(p=0.0047)$ and swollen cervical lymph nodes $(p=0.0253)$.

\section{TABLE 3}

Prevalence of mild upper respiratory and non-respiratory symptoms in non-mumps cases after a youth club party in a village on 9 March 2012, and at time of questionnaire completion (May-June 2012), the Netherlands ( $\mathrm{n}=46$ )

\begin{tabular}{|c|c|c|c|}
\hline & $\begin{array}{l}9 \text { March - } 3 \text { April } 2012 \\
\text { (up to } 25 \text { days after the party) }\end{array}$ & $\begin{array}{l}4 \text { May - } 4 \text { June } 2012 \\
\text { (at time of questionnaire } \\
\text { completion) }\end{array}$ & McNemar chi-squared \\
\hline & n (\%) & n (\%) & $\mathrm{p}$ value \\
\hline \multicolumn{4}{|c|}{ Upper respiratory illness symptoms } \\
\hline Runny nose & $8(17)$ & $4(9)$ & 0.2059 \\
\hline Sore throat & $11(24)$ & $1(2)$ & 0.0016 \\
\hline Cough & $8(17)$ & $1(2)$ & 0.0082 \\
\hline Swollen cervical lymph nodes & $4(9)$ & o (o) & 0.0455 \\
\hline \multicolumn{4}{|l|}{ Other symptoms } \\
\hline Stomach ache & $2(4)$ & $1(2)$ & 0.5637 \\
\hline Myalgia & $2(4)$ & $1(2)$ & 0.5637 \\
\hline Fever & $3(7)$ & $1(2)$ & 0.3137 \\
\hline Loss of appetite & o (o) & $1(2)$ & 0.3137 \\
\hline
\end{tabular}

NA: not applicable 


\section{Discussion}

We describe a mumps outbreak with a $22 \%$ AR following a party at a youth club where over $90 \%$ of outbreak investigation participants had received two doses of MMR vaccine. Smoking at the party and age $\geq 21$ years were independent risk factors for mumps: smokers were three times more likely to become ill than nonsmokers, and individuals aged $\geq \mathbf{2 1}$ years were almost five times more likely to become ill than individuals under 21. In addition to classic mumps disease, our results suggest that prevalence of mild URI was significantly higher around the time of the outbreak compared to a baseline prevalence at the time of questionnaire completion.

The observation that older age was a risk factor for mumps adds to previous evidence suggesting that waning of vaccine-derived immunity may prompt outbreaks [11-14]. As our investigation was conducted online and several weeks after the outbreak, it was not possible to use serology to explore the role of primary versus secondary vaccine failure in more detail through avidity studies; however, IgG avidity testing following a mumps outbreak in a class of highly vaccinated $17-18$ year-olds at a Korean school demonstrated that $73.3 \%$ of the cases had secondary vaccine failure [15]. Together with the previous studies that also found older age groups to be at increased risk in mumps outbreaks, we conclude it is likely that waning immunity was the most likely explanation for older individuals being at higher risk of mumps in our study. A possible explanation for smoking being associated with increased risk could be that the practice of sharing cigarettes may transmit mumps virus via saliva; however, this behaviour was not commonly reported by study participants (data not shown). Alternative explanations could be that smoke may act as a vehicle for inhalation of droplets carrying mumps virus, putting anyone who breathed the contaminated air at increased risk, or simply that smokers were in contact with each other more frequently than were non-smokers. As smoking indoors at the party was prohibited, it is likely that smokers congregated together outside the youth club to smoke, which would support the two latter explanations. Nonetheless, smoking was not identified as a risk factor in similar outbreaks investigated previously $[3,4]$.

Our AR of $22 \%$ seems high in comparison to other studies that found ARs of $2.2-3.6 \%$ in populations vaccinated with the Jeryl Lynn virus strain [5]. It is possible that our study overestimated AR for two reasons: firstly, mumps was self-reported and not confirmed serologically, allowing misclassification. However, in an outbreak context it can be expected that persons experiencing mumps-like symptoms within the incubation period are highly likely to be true cases. Secondly, mumps cases may have been more likely to participate, introducing bias. However, of the 16 cases notified to the MHS who did not respond to the survey and whose date of onset fell within the incubation period, ten reported attending the party. If these ten cases are included in the numerator and all other non-responders are assumed to be non-mumps cases (i.e. making the denominator all the people at the party, estimated to be 100), the estimated AR remains similar at $23 \%$. Two studies in the Netherlands which investigated mumps outbreaks in highly-vaccinated populations following parties found comparable ARs in attendees of $16 \%$ [3] and $23 \%$ [4]. It is likely that intense crowding and perhaps environmental factors at parties contribute to high ARs.

The finding of a significantly higher prevalence of mild URI in non-mumps cases after the party may be suggestive that some infected individuals may present with mild disease and perhaps contribute to further transmission. This hypothesis is further supported by no similar apparent pattern for non-respiratory symptoms. However, care must be taken in interpretation, as numbers were small and mild URI can be expected to be more common in early spring than in summer. Indeed, routine surveillance data suggest that in 2012, more upper respiratory pathogens were circulating in the Netherlands in weeks 10-14 than in weeks 18-23 (personal communication, Rianne van Gageldonk, September 2012), and unfortunately it was not possible to confirm or refute mumps virus infection serologically.

In summary, our study suggests that intense social mixing, waning immunity and smoking contributed to an outbreak of mumps in a highly-vaccinated population attending a party. Crowded social events appear to facilitate high attack rates among vaccinated populations, especially among age groups where there is no natural immunity and where several years have passed since vaccination. Our finding that mumps virus infection of vaccinated individuals may manifest as mild URI may have implications for transmission and warrants further investigation in future studies where serological confirmation is a possibility. Ongoing studies in the Netherlands will study the role of asymptomatic or mild mumps infections in onwards transmission.

\section{Acknowledgments}

We thank I Karagiannis of the European Programme for Intervention Epidemiology Training, $\mathbf{M}$ van der Sande of the Dutch National Institute of Public Health and the Environment, and the anonymous reviewers for critical review of this manuscript. We also thank all respondents for participating in the study. This article is dedicated to $\mathrm{Dr}$ Hein Boot, who sadly passed away during completion of the manuscript.

Conflict of interest

None declared.

Authors' contributions 
GL wrote the outbreak investigation study protocol, participated in the outbreak investigation, analysed the data, and wrote the manuscript SO and TW led the outbreak investigation at the local level and contributed to and reviewed the manuscript RB and HB led the laboratory investigations and contributed to and reviewed the manuscript SH supervised the overall project, contributed to the outbreak investigation study protocol, and contributed to and reviewed the manuscript.

\section{References}

1. Van Lier EA, Oomen PJ, Giesbers H, Drijfhout IH, de Hoogh PAAM, de Melker H. Vaccinatiegraad Rijksvaccinatieprogramma Nederland. Verslagjaar 2011. [National Immunisation Programme in the Netherlands. Annual Report 2011]. Bilthoven: National Institute for Public Health and the Environment (RIVM); 2011. Available from: http://www.rivm.nl/bibliotheek/ rapporten/210021014.html;

2. Whelan J, van Binnendijk R, Greenland K, Fanoy E, Khargi M, Yap K, et al. Ongoing mumps outbreak in a student population with high vaccination coverage, Netherlands, 2010. Euro Surveill. 2010;15(17):19554.

3. Brockhoff HJ, Mollema L, Sonder GJ, Postema CA, van Binnendijk RS, Kohl RH, et al. Mumps outbreak in a highly vaccinated student population, The Netherlands, 2004 . Vaccine. 2010;28(17):2932-6. http://dx.doi.org/10.1016/j. vaccine.2010.02.020

4. Greenland K, Whelan J, Fanoy E, Borgert M, Hulshof K, Yap $\mathrm{KB}$, et al. Mumps outbreak among vaccinated university students assoicated with a large party, the Netherlands, 2010. Vaccine. 2012;30(31):4676-80. http://dx.doi.org/10.1016/j. vaccine.2012.04.083

5. Dayan GH, Rubin S. Mumps outbreaks in vaccinated populations: are available mumps vaccines effective enough to prevent outbreaks? Clin Infect Dis. 2008;47(11):1458-67. http:// dx.doi.org/10.1086/591196

6. Peltola H, Kulkarni PS, Kapre SV, Paunio M, Jadhav SS, Dhere RM. Mumps outbreaks in Canada and the United States: time for new thinking on mumps vaccines. Clin Infect Dis. 2007;45(4):459-66. http://dx.doi.org/10.1086/520028

7. Ladbury G, Ostendorf S, Waegemaekers T, Hahné S. “Liking” Social Networking Sites - Use of Facebook as a Recruitment Tool in an Outbreak Investigation, The Netherlands, 2012. Epidemiol 2012;3:123. doi: 10.4172/2161-1165.1000123. http:// dx.doi.org/10.4172/2161-1165.1000123

8. Wet Beschermings Persoonsgegevens [Dutch Data Protection Act]. The Hague: Government of the Netherlands; 2001. [Accessed 11 December 2012]. Available from: http://www. dutchdpa.nl/Pages/en_ind_wetten_wbp.aspx. Dutch.

9. Wet op de Geneeskundige Behandelingsovereenkomst [Dutch Medical Treatment Act]. The Hague: Government of the Netherlands; 1994. [Accessed 11 December 2012]. Available from: http://wetten.overheid.nl/BWBRoo07021/. Dutch.

10. Gedragscode voor gezondheidsonderzoek [Dutch Code of Conduct for Health Research]. Foundation Federation of Dutch Medical Scientific Societies: Rotterdam; 2004. [Accessed 11 December 2012]. Available from: http://www.cbpweb.nl/Pages/ ged_fmwv_gez_onderzoek.aspx. Dutch.

11. Centers for Disease Control and Prevention. Update: multistate outbreak of mumps-United States, January 1-May 2, 2006. Morb Mortal Wkly Rep. 2006;55:559-63.

12. Cohen C, White IM, Savage EJ, Glynn IR, Choi Y, Andrews N, et al. Vaccine Effectiveness Estimates, 2004-2005 Mumps Outbreak, England. Emerg Infect Dis. 2007;13(1):12-17. http:// dx.doi.org/10.3201/eid1301.060649

13. Vandermeulen C, Roelants M, Vermoere M, Roseeuw K, Goubau P, Hoppenbrouwers K. Outbreak of mumps in a vaccinated child population: a question of vaccine failure? Vaccine. 2004;22(21):2713-2716. http://dx.doi.org/10.1016/j. vaccine.2004.02.001

14. Briss PA, Fehrs LJ, Parker RA, Wright PF, Sannella EC, Hutcheson RH, et al. Sustained transmission of mumps in a highly vaccinated population: assessment of primary vaccine failure and waning vaccine-induced immunity. J Infect Dis. 2004;169(1):77-82. http://dx.doi.org/10.1093/infdis/169.1.77

15. Park DW, Nam MH, Kim JY, Kim HJ, Sohn JW, Cho Y, et al. Mumps outbreak in a highly vaccinated school population: assessment of secondary vaccine failure using IgG avidity measurements. Vaccine. 2007;25(24):4665-4670. http://dx.doi. org/10.1016/j.vaccine.2007.04.013 
